\title{
The Effects of Anti-dengue Media Campaign of Government of Punjab: A Case Study of Gujranwala City
}

\section{Yasir Waseem I*}

Islamia University, Bahawalpur, Punjab, Pakistan

\begin{abstract}
The study "The Effects of Anti-dengue Media Campaign of Government of Punjab: A Case Study of Gujranwala city" conducted to determine the level of awareness of the provincial government anti-dengue campaign on the citizens of the Gujranwala, central Punjab, Pakistan. The study also analyzed to find out the understanding of the residents of Gujranwala about the cause, preventions and identification of dengue disease as well as the effects of the medium on residents. For this study a questionnaire compressing eleven questions was distributed among 300 respondents in district Gujranwala to find out results. The study reveals that the anti-dengue media campaign of the government of Punjab successes due to the use of Television in the area. The finding also exposed that television is the effective source of information for such type of epidemic disease in the Gujranwala particularly and in the country generally. The study supports the theoretical framework of 'Social learning Theory' that emphasized on the importance of observing and modeling the behaviors attitudes and emotional reactions of others. Under the said assumption the citizen of the Gujranwala also get awareness and learn from the media about dengue disease, causes, prevention and identification.
\end{abstract}

Keywords: Media campaign; Source of information; Social learning theory; Behavior and attitudes; Media effect

\section{Introduction}

This study is a conduct to check the effects of anti-dengue media campaign of the government of Punjab. It is conducted on the people of Gujranwala city through survey technique. The question is what the dengue fever is? What are its causes, effects, preventions, treatments, symptoms and latest situation of dengue fever in Pakistan?

\section{Dengue}

Dengue is the worst epidemics disease which humanity has faced. According to control and prevention (CDC) a mosquito transmits viral disease characterized by fever, headache ,artheralgia, nyalgia, rash, nausea and emetine infections are caused by any of four virus stereo types (DEN-1, DEN-2, DEN-3, DEN-4) infection that has become a major international public health concern. The origin of the word "dengue" is not clear but one thinking is that this word derived from Swahili ftnraze ka-dinga pepo which means the disease is being caused by an evil spirit while the word dinga is a Spanish word which mean fastidious are careful. In West Indies this disease was known as dandyfever [1].

Dengue is found in tropical region around the world. Due to this disease about two fifth of the world population are now at risk. Dengue hemorrhagic fever is potentially lethal complication [2].

Media is the best tool which can create awareness against dengue fever are have a potential to influence the people behavior to check the behavior of people regarding dengue this research is conducted.

In 1995 Catford explain the role of media in health promotion. He mentioned various points about the health promotion. Few are given below.

- Rising public and political awareness about disease.

- Creating a climate of opinion for action at individual and environmental level.

- Providing heavy living information and advice.
- Changing attitude by presenting examples role model.

- Introducing skills, encouraging self-confidence.

\section{Impacts}

Dengue is an epidemic disease which is affecting throughout the world. Billions of people of more than hundred countries are at the risk of this disease. 50 million infections, 500000 cases of dengue hemorrhagic fever and 22000 deaths mainly among children occurred in a year [3].

Impacts of dengue fever show that it is very dangerous disease for human being and it is a great threat for future. Due to these impacts it is necessary to find the reasons of this epigenetic being a student of media in this perspective. For this purpose researcher choose the topic "The effects of anti-dengue media campaign of government of Punjab (A case study of Gujranwala city)".

\section{Dengue in world}

Dengue is an infection which is caused by a mosquito. Dengue had proved a major public health concern in world. This disease is found in most tropical and subtropical areas of world. Dengue fever is a hemorrhage disease transmitted by Aedes mosquito called Aedes aegypti. Medical scientist says" four dengue viruses (DEN-1 TO DEN4) are immunologically related, but do most provide cross protective immunity against each other" [4].

According to world health organization, during 1999, 2.5 billion

*Corresponding author: Yasir Waseem I, PhD Scholar, Islamia University, Bahawalpur, Punjab, Pakistan, Tel: +92 62 9250235; E-mail: waseem.yasir@gmail.com

Received July 11, 2017; Accepted August 21, 2017; Published August 24, 2017

Citation: Yasir Waseem I (2017) The Effects of Anti-dengue Media Campaign of Government of Punjab: A Case Study of Gujranwala City. J Mass Communicat Journalism. 7: 344. doi: 10.4172/2165-7912.1000344

Copyright: (c) 2017 Yasir Waseem I. This is an open-access article distributed under the terms of the Creative Commons Attribution License, which permits unrestricted use, distribution, and reproduction in any medium, provided the original author and source are credited. 
people are at risk of dengue virus infection. This virus has spread in 200 countries of the world while before 1970; the dengue was just in nine countries of the world. The mortality rate from the dengue fever in the world is about $5 \%$, which can be reduced to $1 \%$ with proper treatment in the hospital. Dengue viral infection has become the leading public problem. Dengue has become a major viral disease in the world.

\section{Dengue in South Asia}

From two or three years, the dengue is spreading in south Asian countries very fast in the context of dengue fever in south Asia ,Sheppard says" The health burden of dengue in South East Asia only estimated to be 0.42 Disability Adjusted Life Years (DALYs) per 1,000 population $52 \%$ due to premature mortality, $48 \%$ due to morbidity" [5].

All over the world prevalence of dengue was grown dramatically in the recent decades. Not only the number of cases increasing the south Asia. However also explosive out break are occurring as its epidemiological pattern is changing [6]. In 2003, only eight counties in South East Asia Region reported dengue cases. But in 2006, it increased in eleven countries. Bangladesh, Bhutan, India, Indonesia, Maldives, Myanmar, Nepal, Sri Lanka and Timor-Leste reported dengue cases. Bhutan reported the first dengue outbreak in 2004. In 2005 TimorLeste, an outbreak with a high cases fatality rate $3.55 \%$. Korea is the only country in this region that has no reported transmission of Dengue fever [7].

\section{Dengue fever in pakistan}

In Pakistan, first case of dengue fever was reported in Karachi in 1994.

Due to Dengue Viral Infections from September to December 2005, at least 3 major hospitals in Karachi had increase in the number of patients with signs consistent.

Heavy monsoon rains in Punjab has provided ideal atmosphere for dengue-carrying mosquitoes to thrive in stagnant and clean water. The number of Dengue patients is increasing constantly. Seven patients had died on 15th September 2011, while 5,500 Dengue cases have been confirmed in Punjab only. Out of 29 people who died of Dengue in Punjab, 25 were from Lahore. According to the report of Punjab health department, during 2011, some 21292 people were affected from dengue and 345 were died while in 2012, just 261 were affected and there was no any death was happened.

According to Dr Khalid Randhawa District Health Officer, there are more than 30 private hospitals in the Lahore city. He said the number of private clinics with 20 beds was over 1000 .

In less than a month 126 people have died and more than 12,000 have been diagnosed with the virus, which has spread rapidly among both rich and poor in Punjab's capital Lahore.

\section{Dengue in gujranwala}

According to the Executive District Officer health, Dengue Controle Cell (DCC), Gujranwala that 28 cases have been deducted in the district in 2011. He said that all the affected were recovered but these all patients were shifted from the other sounding districts. Responding to the anti-dengue media campaign he appreciated that the provincial government has took positive steps for the eradication of the cause in the area particularly and over the country generally. $\mathrm{He}$ explored that due to the effective media campaign neither dengue case has been deducted in the district Gujranwala in 2012.

\section{Objectives of the study}

- The basic object of the research is to evaluate the role of media for awareness of anti-dengue media campaign by government of Punjab.

- The second objective of this research is to collect the basic data about the dengue fever in the world specifically in Pakistan.

- Another objective of this research is to see the effects of antidengue media campaign.

- Another objective of my research is to prepare communication strategies for government and media practitioners during this kind of issue.

- To dig out the positive or negative effects of media campaign on the issue of dengue.

- Another objective of this research is to know to how the media campaign can initiate effective campaign about dengue fever.

- To examine what kind of media is being used by the people regarding such types of issue.

- To assess the knowledge, attitude and preventive measures regarding dengue fever.

Dengue fever has become epidemic and a fatal disease. There is no proper treatment to overcome this disease. It is necessary to make aware and educate the public through different sources. This research would be helpful in the creation of awareness about dengue fever. It would clarify the causes, symptoms, prevention and realities about dengue fever. It has been seen that media plays an important role in this issue. But it has also seen that media create sensationalism. In this regard this research would also be helpful for media practitioners that where they were wrong and where they create unnecessary hype and how they should have portrayal this kind of issue. It would also be helpful for government to tackle this kind of problem. This research would also be helpful in getting the results of anti-dengue media campaign by the government of the Punjab. All above mention benefits shows the significant of the topic.

With this research we will know about

1. The patients of dengue in the world particularly in Pakistan.

2. This untreatable disease and its fatalness.

3. How can we protect ourselves from this dangerous disease we will also know that what are the effects of media campaign by the government of Punjab.

The study has been conducted to investigate the effects of antidengue media campaign of government of Punjab on the citizens of Gujranwala. This research would particularly focused on the role of media, basic information about dengue fever, effects of dengue and communication strategies prepared by government of Punjab regarding dengue fever disease.

\section{Literature Review}

According to the National Institute of Allergy and Infection Diseases (NIAID) [8] dengue is an infection caused by an infected mosquito. It is a virus common wet area born in rainy season. The institute recommended that the internet source is more effective in the developed countries rather than social and mainstream media of the country. Charless and Devid [9] argued that the local media is impressive for the awareness of the public about the dengue fever [10] 
concluded in his research examined the awareness technique about the disease. He digs out that newspapers could better inform the public about the dengue fever in the world. Leumnen [11] described that mass media could be effective for the prevention of the dengue disease.

Patrick and Chaltin [12], concluded in his research, that the use of static media is beneficial for the rural public. Nadeem Crack conducted research on "Dengue fever hits life neighborhoods of Lahore" concluded that dengue was first recognized in 1950,s in the Philippines, Pakistan and Thailand. He also mentioned that this disease is a new prevails. $\mathrm{He}$ also described that dengue outbreak surrounding of Lahore and it can't be defeated without the participation of the community. The researcher investigates the informative sources. He argued the folk media is better informative source for the remote areas.

Mansoor Gilani, concluded in research titled "Dengue fever infects over 1, 2000 in Pakistan" that television and newspapers are the best form of information to prevent the public from the dengue fever in the country.

Alanl Rothman mentioned in his research article that the use of mass media could control the dengue fever in the developing countries in the globe.

Atiya Mehboob concluded in her research tilled" Clinical Characteristics of Patients with Dengue fever: Report of 48 patients in 2010" She argued that such type of information through the media could control the dengue fever.

Aisha Sajid concluded in her research that to prevent the children from the dengue virus by the cartoon programs through the televising.

Gobbler [13] mentioned in his research that the rapid death could be control through face to face communication and public message.

Naila [14] determined that the use of radio and television was the best source for the awareness of disease such as dengue virus.

Faisal et al. [15] conducted a research on the "knowledge and attitude of the public towards dengue control in the urban and rural areas of the Punjab" concluded that public has not a wide range of knowledge, but the respondent are well informed about the habit of the mosquitoes, ways to prevent of the disease protection techniques from dengue fever.

Katherine [16] described in her research that this type of epidemic disease could control through the usage of print media.

Endy et al. [17] recommended to the governments to launch the media campaigns in the rainy season about the prevention of mosquitoes.

Eng-Eohgooi, suggested reducing victor population from the prevention of the disease. He said that the public awarded by the radio dengue awareness programs.

Farakh [18] prescribe in his research "Dengue fever in Lahore" that 2.5 billion people are at the risk of dengue fever in 200 countries. $\mathrm{He}$ also describe in his research that mortality rate is about 5 percent in this disease which can be reduce to one person through proper treatment. He concluded about the dengue virus in Lahore that this disease is spreading rapidly in the city. She mentioned in her report that people of the Lahore had received the information through the cable television and government media campaign against the disease.

Akhtar [19] conducted a research on "Dengue fever: a major public health Concern in Pakistan" that the most rapidly spreading victor born viral disease in the world is dengue fever. He said that in the big cities in the country such as Lahore and Karachi were informed through the media government campaign which highlighted the causes and prevention of the dengue fever.

Mohsin [20] mentioned in his research "Public awareness towards dengue fever in Lahore" that 93 percent people of Lahore city are aware of dengue fever but only 59 percent are knows about the fever. Researcher explore that 75 percent people knows about the dengue fever through TV and newspaper while 8 percent claim to know through internet.

Jahan [21] describes in his research "Dengue fever in Pakistan" that dengue is a wide spread mosquito born infectious disease which has become danger for public health it is basically a virus which can be cause of death. He focuses on the awareness about the systems of this disease to reduce the large complications. She said that a campaign should be launch against the viral mosquitoes in the country through the media to control the disease.

Susan Young [22] conducted a research on "Pakistan uses Smartphone data to head of Dengue outbreak" that Pakistan government use smart phone to aware public through message. It assigns duty to 1500 employs to inform other people and a central command about dengue confirmed cases their locality and time.

Shepard [23] prescribed in his research "Overcoming data elimination: design of multiple components study for estimating the economic burden in India" that dengue is a global health issue it damage economic of the different countries and increase the economic burden of the government. He suggested that this economic burden can be decrease through awareness about the dengue fever by government campaigns on the mainstream media of the country.

Verman et al. [24], describe in his research "Capillary Leak Syndrome in dengue fever" that Capillary Leak Syndrome (CLS) has been prescribed in dengue fever but its original and pure features are not define with clarity but with some causes and symptoms we will able to diagnose this disease of dengue fever and to control it. He stated that dengue fever diagnosing system must interpret through the media for the awareness of the public is most important than the prevention campaign.

\section{Research questions}

1. How much awareness is in the educated and uneducated people regarding dengue?

2. How much anti-dengue media campaign remained effective in Gujranwala city?

3. What kind of awareness related through anti-dengue media campaign of government of Punjab?

4. What are the effective sources of awareness?

5. How can improve such kind of awareness campaign?

6. Is anybody affected through dengue fever in Gujranwala city?

\section{Methodology}

Research methodology is a method through which the researcher completes his research. It is a procedure adopted for making research. The researcher chose survey method as a research design to dig out "The effects of anti-dengue media campaign of government of Punjab in Gujranwala city". In this study all population of Gujranwala 
considered as the universe of the study. The population of this research study includes different groups of society like teachers, students, businessmen, household women, labors, employs and jobless. Quota sampling is used for gathering data while quota sampling is "a method of gathering data from a group". (Business dictionary). The sample size is 300 respondents of the Gujranwala city male and female, educated and uneducated. In this research the simple questionnaire was constructed for survey. First constructed in Urdu and then translated into English for the analysis. Close and open ended questions were formulated and try to specify and short it. The researcher used SPSS, Microsoft excel and in page for Urdu questionnaire. SPSS is a statistical package which is used for statistical analysis.

\section{Operational and formal definitions}

Operational and formal definitions of different words used in research topic are given here so there the other researchers can easily understand the meaning of these words related to research

Campaign: Formal definition of campaign is "an organized course of action to achieve a goal: an election campaign etc". (Oxford dictionary)

Effects: Formal definition of effect is "The power to produce an outcome are achieve a result; influence" while the operational definition related to researcher is the effect of anti-dengue media campaign on people of Gujranwala city.

Anti-dengue: According to researcher any activity against the dengue fever is called anti dengue.

\section{Data interpretation}

No one can deny the effective role of media in the development and promotion of the different sectors as well as every aspect of life all over the world. But also bears failure due to some factors such as production and dissemination of inappropriate message, selection of proper actor, use of unsuitable medium and lack of evaluation of the program.

In the context of other countries of the world, the media also has been used by the government of Punjab, Pakistan for the control and eradication of dengue fever disease in the country. The researcher got interest in digging out the factors of success and failure of Punjab provincial government media campaign against dengue disease, particularly in the residents of Gujranwala. The researcher has selected the Gujranwala city for the research, while the result would be generalized for the other researcher in the field and for the benefit of the government of the Pakistan.

A total of 300 respondents of Gujranwala city filled the questionnaire, 156 (52\%) of them were male and 144 (48\%) were female. As shown in Table 4.1, majority of respondents uneducated 155 (55\%), while 135 (45\%) educated in the area. Majority of respondents between 26 and 35 years old (47\%), followed by aged $15-25$ years old (35\%) respectively of the total population of Gujranwala city. The researcher has classified the respondents into different profession according to the area situation to dig out the percentage of that who is more exposing to media in the area. The data that skillful and labor class $85(28.3 \%)$ of the Gujranwala city has exposing to media more than the Households 55 (18.3\%), employees $46(15.3 \%)$, students $36(12 \%)$, teachers $33(11 \%)$, businessmen $29(9.7 \%)$ and jobless $16(5.3 \%)$ respectively exposed to the dengue eradication provincial media campaign in the Gujranwala city (Figure 1).

Figure 2 the awareness level of the respondents about the dengue

\section{Awareness Level}

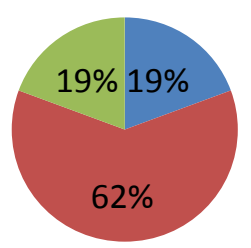

Completely

Somehow

Not at All

Figure 1: Awareness Level of the Respondents about Media Campaign.

abolition media campaign. $58(19 \%)$ of the respondents completely Know, 184 (62\%) know somehow and 58 (19\%) of respondents do not know about the Punjab government anti dengue media campaign.

Figure 3 the medium of source of information through which the respondents acquire information of the dengue annihilation media campaign of the Punjab government.

The respondents out of 300, 74 (24\%) got the information through the Newspapers advertisements, 37 (12.3\%), with radio advertisements, $86(28.7 \%)$ on television advertisements, $13(4.3 \%)$ by Seminars, 20 (6.7\%) via posters, $10(3.3 \%)$, used pamphlets, $12(4 \%)$ and $1(.3)$ read banners and all chalking, 18 (6\%) read text books, $14(4.7 \%)$ used other sources and $15(5 \%)$ have no source of information. The result shows that the most of the respondents have got the information through the Television advertisements in the Gujranwala city of Punjab.

Figure 4 the distribution according to the identification about the dengue disease. $110(36 \%)$ said that it is a disease which spiral a virus in the society. $126(42 \%)$ agreed that it is the name of the mosquito, $35(12 \%)$ think a name of disease and $29(10 \%)$ don't know about the dengue fever in the Gujranwala city of Punjab province, Pakistan.

Figure 5 the reasons of the dengue fever according to the residents of Gujranwala. 73 (24\%) said that it is a bacteria spreading disease, 134 (45\%) think a virus spiral disease, 35 (12\%) replied other reason of the dengue fever and 58 (19\%) don't know about the cause of the dengue fever. The result shows that most of the residents 134 (45\%) replied that it is a viral disease and spreading through virus among the society.

The researcher asked about the effect of the dengue fever on the respondents or their relatives. Figure 6 illustrates that $89(30 \%)$ replied that it is affected them and their relatives, while $211(70 \%)$ answered that dengue fever didn't affect them and neither their relatives.

The researcher asked about the identification about the disease that how the respondent and their relatives know the dengue fever. Figure 7 the exemplify that $15(5 \%)$ that identified by the symptoms, $18(6 \%)$ replied that some other identified, 46 (15\%) answered doctor diagnosed and $12(4 \%)$ responded that it identified by other sources. Due to the supplementary question most of the respondents 209 (70\%) exempted the answer to question.

Responding to the open-ended question about the prevention measure of dengue disease, the researcher classified the answers into three categories know, somehow and not at all. The respondents who mention detailed prevention measures those would be considered in the category of "know", who mention one or two would be "somehow", while who didn't mention any measure would be consider "Not at all".

Who know the precaution measures of dengue fever in the Gujranwala city, Punjab province, Pakistan. Out of 300 respondents, 


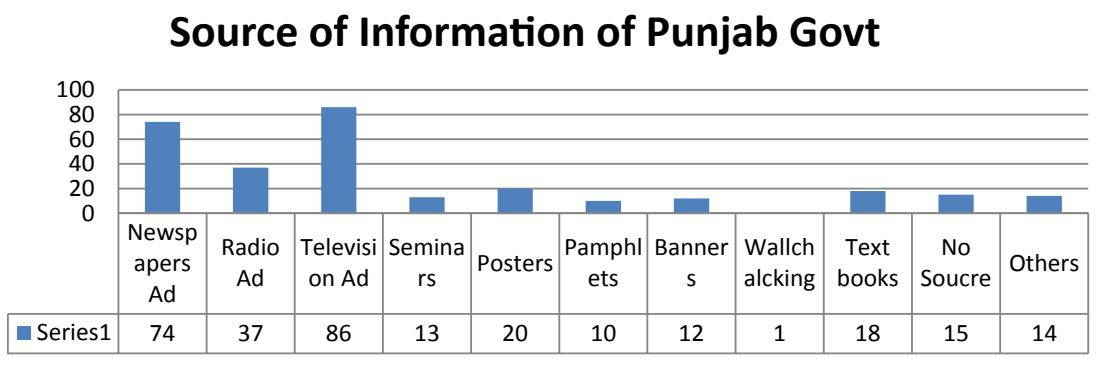

Figure 2: Source of Information of the respondents of the Media campaign.

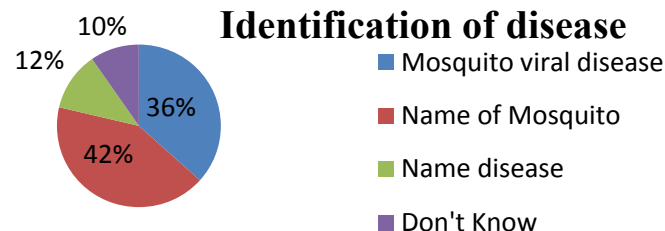

Figure 3: Distributions of respondents according to the identification about the dengue disease.

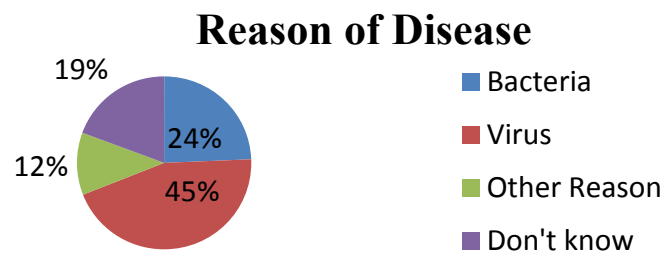

Figure 4: Reason of disease according to the Residents of Gujranwala.

\section{Effect on Respondents \& Relatives}

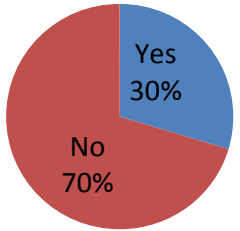

Figure 5: Affected the respondents or relatives by the dengue fever.

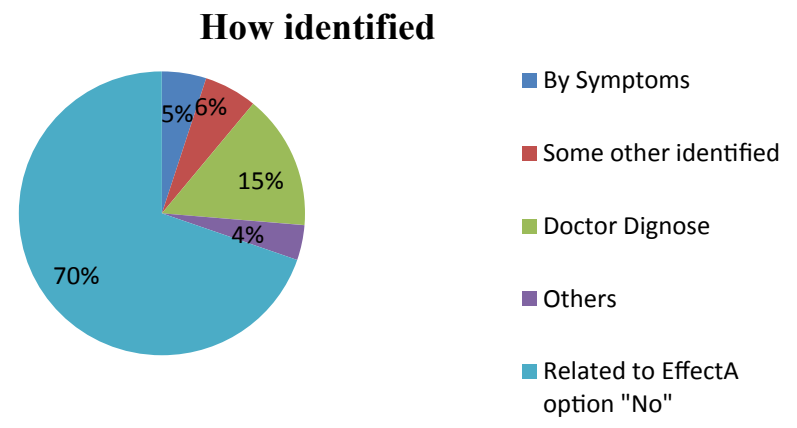

Figure 6: How the respondent identified the disease.

24 (8\%) replied that they know, 204 (68\%) answered somehow and 72 (24\%) agreed that they didn't know about the precaution measures of the dengue fever (Figure 8).

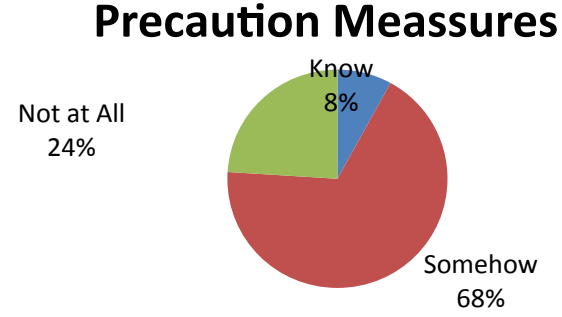

Figure 7: Distribution of Respondents who know the precaution Measures.

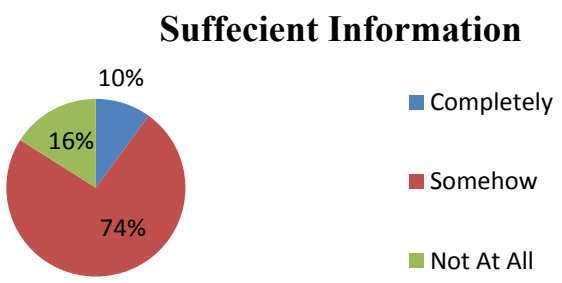

Figure 8: Opinion of respondents about the information given by the Punjab government anti-dengue media campaign.

Public know about the disease prevention

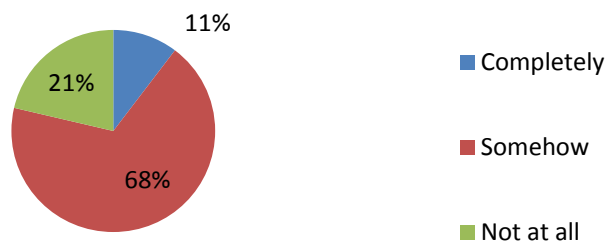

Figure 9: Public know about the prevention measures of the disease.

- The researcher inquired about the information given by the Punjab government anti-dengue media campaign. Majority of them $222(74 \%)$ replied that the information disseminated by the provincial government of Punjab sufficient information about the dengue disease, $30(10 \%)$ answered it was most sufficient, while $48(16 \%)$ think that the government of Punjab media campaign about the dengue fever has not given sufficient information to the public in the province (Figure 9).

Responding to a query the residents of Gujranwala said that 31 (11\%) completely knew, 205 (68\%) knew somehow and 64 (21\%) didn't know about the prevention measures of the dengue viral disease in the area. The result shows that the most of the residents of Gujranwala city somehow know about the prevention of the fever (Figure 10).

To a query about the successfulness of the provincial media 
anti-dengue campaign the respondents out of 300,45 (15\%) think successful, 191 (64\%) agree somehow and $64(21 \%)$ did not agreed to the successfulness of anti-dengue media campaign of government of Punjab. The Graph show that most of the respondents agree that the media campaign by government of Punjab was somehow successful in the Gujranwala city, south Punjab, Pakistan.

Figure 11 illustrates the view of the respondents about the most effective source of information for the anti-dengue media campaign in the country. 58 (19\%) replied Newspaper advertisement, 38 (13\%) think radio advertisement, 111 (37\%) agreed Television advertisement, 19 (6\%) specified seminars, $18(6 \%)$ think posters, pamphlets, banners, wall chalking and text books ranked $4 \%, 3 \%, 2 \%$ and $6 \%$. While $6(2 \%)$ selected other sour of information in which they mentioned doctors, teachers and opinion leaders of the society could effective the antidengue media campaign in the province.

Responding to the open-ended question about the suggestions for the betterment of anti-dengue media campaign, the researcher classified the answers into three categories mention, somehow and not at all. By the mention option the researcher means that the respondents have given recommendations to the government. 30 (10\%) presented different suggestions for the government as well as for the media practitioners that the government should organized teams for the awareness about dengue disease such as polio campaign, face to face communication such as seminars, use the Imam Masjids, Nuberdaars, Nazims and councilors to aware the community through local languages, train the school, colleges and university teachers to communicate the cause and prevention to students. The women among the respondents suggested to the government to train and organized female anti-dengue campaign to make aware the households of the communities in the country, because according to our culture and tradition the domestic members are not allowed to attend any seminar or workshop for the awareness outdoor.

The respondents who suggested somehow for the government are 137 (46\%) (Figure 12). These respondents also presented suggestion for the betterment of government campaign. 133 (44\%) didn't mention their views for the improvement of the anti-dengue media campaign of the provincial government. The result demonstrates that the anti-

\section{Opinion about Punjab Govt Campaign}

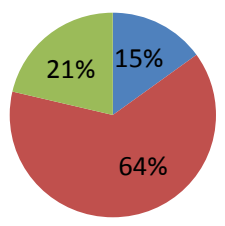

Completely

Somehow

Not at All

Figure 10: Opinion about the successfulness of Punjab Government. dengue media campaign of government of Punjab has presented the reason of the dengue fever because the residents of Gujranwala city knew the disease.

\section{Findings and Results}

The researcher asked about the level of awareness about the anti-dengue media campaign by government Punjab. 62 percent respondents denied the awareness of the media campaign of the provincial government. The researcher asked a supplementary question through which medium they got the awareness and information about the dengue fever. The respondents exemplify that they got the awareness information mostly by television. 29 percent have selected television advertisement and 24 percent newspaper advertisement for the attentiveness of the disease. The results show that television is the medium mostly used among the citizens of Gujranwala city, south Punjab of Pakistan.

Responding to a query "what do you know about the dengue"? 42 percent among the respondents said that it was the name of mosquito, 36 percent replied that it is viral disease, 12 percent said that it is a name of disease and 10 percent don't know about the dengue. The result shows that the most of the people of the Gujranwala know that it is a viral disease.

The researcher asked a question about the reason of spread of the disease in the society. 45 percent people replied that it is spreading via virus among the people. 24 percent answered that it is spreading through bacteria. The result shows that the people know that it is spreading though the virus. Answer to a question about the effect of dengue disease on them or their relatives. Just 30 percent people have affected by the dengue fever and 70 percent didn't. The result illustrates that dengue fever didn't affect the citizens of the Gujranwala. About the identification of the disease, 15 percent replied that it was diagnosed by the doctor, 5 percent answered that they identified it by symptoms and 6 percent by soe other identified. The result point up that the due to the diagnose of the doctors they got the information of the dengue fever. The results denied the effect of the media campaign of the provincial government, because just 5 percent of respondents have identified it by symptoms which are disseminated through the media.

Responding to the open-ended question about the preventive measure of dengue disease, the researcher classified the answers into three categories know, somehow and not at all. The respondents who mentioned detailed preventive measures, would be considered in the category of "know", who mention one or two would be "somehow", while who didn't mention any measure would be consider "Not at all".

Figure 8 shows those who know the precaution measures of dengue fever in the Gujranwala city, Punjab province, Pakistan. Out of 300 respondents, $24(8 \%)$ replied that they know, 204 (68\%) answered

\section{Effective source of Information}

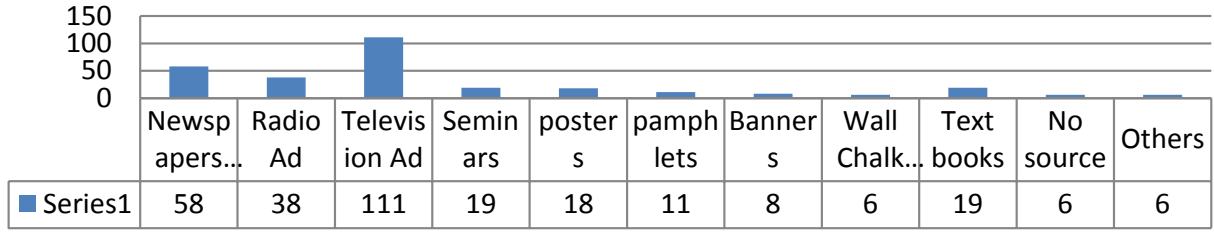

Figure 11: Distribution of respondents according to the effective source of information for the anti-dengue media campaign 


\section{Suggestions for improvement}

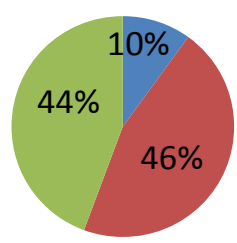

Mention

Somehow

Not at all

Figure 12: Suggestions of the respondents for the promotion of Antidengue media campaign.

somehow and $72(24 \%)$ agreed that they didn't know about the preventive measures of the dengue fever.

To know the opinion of the public about the anti-dengue media campaign presented in the Punjab. The result shows that 74 percent of the residents of Gujranwala acknowledged that the information given by the provincial government was sufficient, While 16 percent denied the fact.

To know the awareness about the preventive measures, the citizens of Gujranwala said that 11 percent completely know about the dengue disease, 68 percent of them somehow know, whereas 21 percent didn't know the prevention measures of the dengue virus.

The results show that the residents of Gujranwala city agree to the fact that the anti-dengue media provincial campaign was successful in the area. 79 percent of them agreed while 21 percent denied the successfulness of the media campaign against dengue.

The result illustrates the opinion of the respondents about the most effective source of information for the anti-dengue media campaign in the country. $58(19 \%)$ replied of Newspaper advertisement, 38 (13\%) think of radio advertisement, 111 (37\%) agreed Television advertisement, 19 (6\%) specified seminars, 18(6\%) think posters, pamphlets, banners, wall chalking and text books ranked $4 \%, 3 \%, 2 \%$ and $6 \%$. While $6(2 \%)$ selected other source of information in which they mentioned doctors, teachers and opinion leaders of the society could effective the anti-dengue media campaign in the province.

Responding to the open-ended question about the suggestions for the betterment of anti-dengue media campaign, the researcher classified the answers into three categories 1 mention, 2 somehow and 3 not at all. By the mention option, the researcher means that the respondents have given recommendations to the government. $30(10 \%)$ presented different suggestions for the government as well as for the media practitioners that the government should organized teams for the awareness about dengue disease such as polio campaign, face to face communication such as seminars, use the Imam Masjids , Numberdaars, Nazims and councilors to aware the community through local languages, train the school, colleges and university teachers to communicate the cause and prevention to students. The women among the respondents suggested to the government to train and organize female anti-dengue campaign to aware the households of the communities in the country, because according to our culture and tradition the households are not allowed to attend any seminar or workshop for the awareness outdoor.

Figure 12 shows the respondents who suggested somehow for the government are $137(46 \%)$. These respondents also presented suggestions for the betterment of government campaign. 133 (44\%) didn't mention their views for the improvement of the anti-dengue media campaign of the provincial government.

\section{Conclusion}

This study was conducted to find out the effects of anti-dengue media campaign of government of Punjab on the residents of Gujranwala city. The researcher has selected 300 respondents as a sample from the citizens of Gujranwala. The researcher selected the population through quota sampling method, which comprises 156 males and 144 females. The researcher sub-divided into four categories according demographic characteristics including gender, age, education and profession. Age was categorized into four groups e.g. 15 to 25,26 to 35,36 to 45 and above. Education wise distribution has been made according to the ratio of the population in the area. Educated category comprises literate respondents and uneducated category comprises illiterate respondents.

The researcher divided the respondents into different categories including businessmen, employees, teachers, students, households, skillful/ labour class and the jobless.

The searcher used survey technique for the data collection. A designed questionnaire was distributed among the respondents comprises 11 questions in which 9 questions were close-ended while two were open-ended. The researcher explained the purpose of the study and got filled the questionnaire. For the illiterates the researcher conducted verbal interviews to collect the data. For the female respondents the help of female coordinators was taken. The researcher has also faced various difficulties in data collection from the uneducated respondents. Because the understanding of questionnaire was a problem for them, so the researcher first explained the questionnaire in local language then ticked the option selected by them.

The objective of the research was denied by the result of the study because 62 percent of the respondents didn't agree to the success of the Punjab anti-media campaign.

The result of the study strongly supported the second objective of the study that it is a viral spreading disease. The result of the study verified that the respondents also knew the causes and reason of the dengue fever.

The result of the study also supported the objective of the study that major portion of the respondents declared that the anti-dengue media campaign by provincial government was successful in the Punjab. The proved of the study also verified that the 37 percent among the respondent recommended that television is the effective source for the elimination of this type of issue in the country. The study also confirmed that anti-dengue media campaign by the government of Punjab, Pakistan has given sufficient information to them about the dengue disease.

The result of the study validated the perception of the study that 56 percent of the respondents had suggested to the government to organize teams for the awareness about dengue disease such as polio campaign, face to face communication such as seminars, use the Imam Masjids, Numberdaars, Nazims and councilors to make aware the community through local languages, train the school, colleges and university teachers to communicate the cause and prevention to students. The women among the respondents suggested to the government to train and organized female anti-dengue campaign to make aware the households of the communities in the country, because according to our culture and tradition the households are not allowed to attend any seminar or workshop for the awareness outdoor.

The results also verified that through which medium they acquired the information, 29 percent of the respondents relied on television and 24 percent selected newspapers. The result of the study also confirmed 
Citation: Yasir Waseem I (2017) The Effects of Anti-dengue Media Campaign of Government of Punjab: A Case Study of Gujranwala City. J Mass Communicat Journalism. 7: 344. doi: 10.4172/2165-7912.1000344

Page 8 of 8

that they knew about the prevention of the dengue fever which they got through the television.

The result demonstrates that the anti-dengue media campaign of government of Punjab has presented the reason of the dengue fever due to that the residents of Gujranwala city knew the disease. Findings supported the theory of research (Social Learning Theory) because $65 \%$ respondents answered that they got awareness about dengue through television, radio and newspapers. These finding shows that people learn from media and media is the integral part of the society so researcher can say that the findings support the social learning theory.

\section{Recommendations}

In the light of findings of the research, some recommendations for media practitioners, government, and common people also for the further studies are given bellow.

- Local media such as FM Radio and newspapers should focus on such kind of issue so that the public of the remote areas can get awareness about those issues.

- Media should focus on objectivity and reality of the issue.

- Campaign should be in the local languages.

- Campaign should be formulated in simple and understandable way.

- Such type of campaign should be in all local and national newspaper, TV channels and on radio stations so that no one can escape from the public campaign message.

- The government should organize seminars and workshops for face to face communication.

- Government should use the different community members (opinion leaders) such as imam masjids, numberdars, nazims and councilors to aware the community through local languages.

- Train the university, college and school teachers to aware the students about causes and prevention of such type of disease.

- Government should trained and organize female anti dengue campaign to aware the households of the communities in the country.

- People should focus of the media awareness campaigns and to act upon such type of information.

- Opinion leaders should convey to the lay man.

- There are some suggestions to the future researchers for the further studies related to dengue disease.

- The effects of anti-dengue media campaign of government of Pakistan on national level.

- A comparative study of Daily Dawn \& Daily the News about the coverage of dengue virus.

- Content analysis of anti-dengue media campaign in Pakistani print media.

- Portrayal of dengue virus in Pakistani electronic media and its impacts on public.

- A case study of anti-dengue media campaign in local newspapers and FM Radio.

- A study about the effects of local languages regarding anti dengue media campaign.

\section{References}

1. Martina BE, Koraka P, Osterhaus AD (2009) Dengue virus pathogenesis: an integrate view. Clin Microbial Rev 22: 564-581.

2. WHO media centre (2009) Dengue and dengue hemorrhagic fever. World health organization.

3. Anonymous (2006) Etymologia dengue. Emerg Infec. Dis. retrieved from 12: 893

4. Centre for Disease [CDC] Health Centre. (2007). Center for disease control dengue fever.

5. Shepard DS (2004) Dengue vaccine.

6. Gubler DJ (1998) Dengue and dengue hemorrhage fever. Clinical Microbiology Reviews 11: 480-496.

7. WHO Regional East Asia. (2007) Dengue hemorrhagic fever: diagnosis treatment, prevention and control (2nd edn.), Geneva: World Health Organization 12 Office for South -23 .

8. National institute of allergy and infection diseases report (2010).

9. Devid, Charless (2011) Dengue fever. New York, America.

10. Nattleman, Marry (2009) Dengue Symptoms and Signs. New York, America.

11. Leunen KL (2010) Dengue Fever Overview. Irish Scotland.

12. Chaltin, Petric (2011) Dengue or break bone fever. World health organization, UNO Geneva.

13. Gubler , DJ, Ooi (1997) Dengue and dengue hemorrhagic fever. CABI First edition United Kingdom 149.

14. Naila (2011) Dengue Infection; study for evolution of enzyme immunoassay (EIA) test for rapid diagnosis. Professional Medical Journal 18: 687-692.

15. Hafeez F, Waseem A, Anjum S, Muhammad A ( 2012) Knowledge and attitude of the public towards dengue control in urban and rural areas of Punjab. Pakistan Journal of Zoology 44: 15-21.

16. Katherine W (2003) Dengue fever. The Rosen Publishing group 2012.

17. Endy TP, Weaver SC, Hanley KA (2010) Dengue virus-Past Present and Future.

18. Farakh AK (2011) 'Dingi' (Dengue) Fever in Lahore.

19. Akhtar S (2011) Dengue fever: A major public health concern in Pakistan. 3: 1-3.

20. Mohsin M (2011) Public awareness towards dengue fever in Lahore.

21. Jahan F (2011) Dengue fever in Pakistan. 10: 1.

22. Rojahn SY (2012) Pakistan uses smartphone data to head off dengue outbreak.

23. Shepard S (2011) Overcoming data limitations: design of a multi component study for estimating the economic burden of dengue in India. Dengue Bulletin 35.

24. Verman SK, Gutch M, Agarwal A,Vaish AK (2011) Capillary leak syndrome in dengue fever. Dengue Bulletin. 35: 65. 